\title{
Accelerometry and physical activity questionnaires - a systematic review
}

Stephanie Skender ${ }^{1,2}$, Jennifer Ose ${ }^{6}$, Jenny Chang-Claude ${ }^{3}$, Michael Paskow $^{1,2}$, Boris Brühmann $^{1,2}$, Erin M. Siegel ${ }^{4}$, Karen Steindorf ${ }^{1,2,5}$ and Cornelia M. Ulrich ${ }^{1,2,6,7^{*}}$

\begin{abstract}
Background: The aim of this study is to review accelerometer wear methods and correlations between accelerometry and physical activity questionnaire data, depending on participant characteristics.

Methods: We included 57 articles about physical activity measurement by accelerometry and questionnaires. Criteria were to have at least 100 participants of at least 18 years of age with manuscripts available in English. Accelerometer wear methods were compared. Spearman and Pearson correlation coefficients between questionnaires and accelerometers and differences between genders, age categories, and body mass index (BMI) categories were assessed.

Results: In most investigations, requested wear time was seven days during waking hours and devices were mostly attached on hips with waist belts. A minimum of four valid days with wear time of at least ten hours per day was required in most studies. Correlations ( $r=$ Pearson, $\rho=$ Spearman) of total questionnaire scores against accelerometer measures across individual studies ranged from $r=0.08$ to $\rho=0.58(P<0.001)$ for men and from $r=-0.02$ to $r=0.49$ $(P<0.01)$ for women. Correlations for total physical activity among participants with ages $\leq 65$ ranged from $r=0.04$ to $\rho=0.47(P<0.001)$ and from $r=0.16(P=0.02)$ to $r=0.53(P<0.01)$ among the elderly $(\geq 65$ years). Few studies investigated stratification by BMl, with varying cut points and inconsistent results.

Conclusion: Accelerometers appear to provide slightly more consistent results in relation to self-reported physical activity among men. Nevertheless, due to overall limited consistency, different aspects measured by each method, and differences in the dimensions studied, it is advised that studies use both questionnaires and accelerometers to gain the most complete physical activity information.
\end{abstract}

Keywords: Accelerometry, Questionnaires, Physical activity measurement, Adults

\section{Background}

Physical activity (PA) is related to a number of health outcomes. According to the Global Recommendations on Physical Activity for Health by the World Health Organization (WHO), physical inactivity is the fourth leading risk factor for all deaths, and regular participation in PA reduces the risk of coronary heart disease and stroke, diabetes, hypertension, depression, breast and colon cancer [1].

\footnotetext{
* Correspondence: neli@hci.utah.edu

'Division of Preventive Oncology, National Center for Tumor Diseases (NCT), Im Neuenheimer Feld 460, 69120 Heidelberg, Germany

${ }^{2}$ Division of Preventive Oncology, German Cancer Research Center (DKFZ), Im Neuenheimer Feld 460, 69120 Heidelberg, Germany

Full list of author information is available at the end of the article
}

PA is defined as any bodily movement that results in energy expenditure [2]. Aerobic, muscle-strengthening, bone-strengthening activity, and stretching are the four main types of PA [3]. It is a complex behavior and, thus, challenging to measure. Different methods to measure PA exist, including behavioral observations, questionnaires, PA diaries, direct/indirect calorimetry, and motion sensors, such as accelerometer, heart rate monitors (HRM), combined heart rate and accelerometry devices and pedometers. Due to the many different methods available to measure PA, there is a lack of comparability among studies. Furthermore, a number of challenges need to be considered for the various methods including expense, time, recall-bias and equipment needs. While the doubly labeled water (DLW) method is the most 
costly measurement, the most cost-effective measurement is the administration of PA questionnaires, which can assess all types of PA and can be used in large samples. They can also cover longer time frames which, however, may also lead to recall bias. PA questionnaires have been generally designed to minimize these potential biases as much as possible. For example the Global Physical Activity Questionnaire (GPAQ) asks about a "typical week" to reduce the need for longer recall [4].

Due to the complex and subjective information collected PA questionnaires may also over- or underestimate participants' PA $[5,6]$. In particular, older adults are more likely to engage in light- to moderate-intensity PA, which is the most difficult type of activity to be assessed by questionnaires [7]. Motion sensors, such as pedometers or accelerometers are increasingly implemented as an additional measure of PA in a free-living environment. Accelerometry has become a common tool in recent studies [8]. Accelerometers are small electronic devices that record acceleration associated with body movement and provide an objective estimate of duration and intensity of locomotion [9]. Today, a multitude of different accelerometers from a number of companies are on the market. They are generally able to assess PA in at least three axes (vertical, horizontal, and perpendicular). A typical output of accelerometer measurements is expressed in activity counts per unit of time, most frequently, counts per minute. In order to make the data comparable across types of accelerometers or types of PA measurement, activity counts can be translated into quantitative estimates of energy expenditure [10]. Each accelerometer model has its own algorithm to convert accelerometry counts into kilocalories (kcals) or metabolic equivalent of tasks (METs). This may lead to different output values depending on the model used so that one cannot directly compare data from different models. Accelerometers are designed to measure all PAs, however, they have also limitations. Depending on the attachment site, single accelerometers are not able to detect all movements, (e.g., upper/lower body or stationary movement) or capture the context in which the measured activities take place (e.g., leisure time or work). They are not suitable for long-term measurements, hence, repeated administration of accelerometers is of great importance in order to assess seasonable variation in PA. Water-based activities may also lead to misclassifications of an individual's PA profile, because not all devices are waterproof, thus must be removed during such activities. Their administration is logistically more complex and costly.

In a publication on best practices of PA monitors by Matthews et al., the authors state that there is a variety of possible wear positions and that a wear-period of 7 days may be sufficient [11]. However, they suggest that further research is needed to inform the appropriate wear-time. Additionally, the daily required wear time is of strong interest, as it has been shown that modifications lead to significant differences in PA measures and adherence $[12,13]$. Data collection is very dependent on compliance by the participant to wear the device. Prior research indicates that healthy participants who are younger, unemployed or current smokers are more likely to be noncompliant [14]. This variance in compliance is less likely to occur in cancer patients, as these are often motivated to modify their lifestyles [15]. This is underlined by the results of a prior study in colorectal cancer patients that reported no significant differences in compliance of wear-time by age, gender, BMI or tumor stage [16].

Many recent investigations combined the use of questionnaires and motion sensors in order to collect complementary and comprehensive data. Several systematic reviews have been performed comparing objective versus self-reported PA $[17,18]$. However, these reviews focused on different domains compared to this presented review. Prior research articles and questionnaires predominantly focused on a specific type of PA (e.g., leisure time, work). The GPAQ, however, is a more recently used instrument to assess several types of PA and thus, may be able to provide a more complete impression of an individual's level of PA. It may be of future interest to review correlations between multimodal PA questionnaires such as the GPAQ and accelerometer data, when this method has been applied more often.

The objective of this study is to review accelerometer settings and wear methods to determine whether a practical standard for settings/wear methods exists. Furthermore, the aim is to determine correlations between accelerometry and PA questionnaire data, overall, and by gender, age and BMI. We believe that our approach using a large set of studies and stratifying on specific subgroups helps to fill gaps in our understanding of PA assessment types in multiple populations.

\section{Methods}

A total of 57 full articles published on simultaneous PA measurement in adults with accelerometry and questionnaires in free-living conditions were reviewed. A literature search was conducted in PubMed in July 2014. Search terms included "accelerometry", "accelerometer", "accelerometers", "motion sensor" or "motion sensors", and "questionnaire" or "questionnaires" and had to be identified in the title or abstract. For all publications, the following inclusion criteria were applied: (1) All participants within each study had to be adults (18+ years) to reduce age-related differences in PA patterns and (2) relevant investigations had to include a sample size of at least 100 participants to increase stability of the observed associations and to allow investigation of 
differences by age, sex and body mass index (BMI). The following exclusion criteria were applied to improve study comparability: (1) studies with wheelchair-using or non-ambulatory participants (2) articles not available in English, and (3) investigations lacking correlation data between accelerometry and questionnaires. Two authors (SS, MP) independently screened and extracted data from the studies according to the above mentioned criteria, regardless of publication date. Disagreements were discussed between the two authors and then resolved.

For this review, all investigations providing correlational comparison values between the different types of PA measurements for the purpose of validity assessment are presented and distinguished by sex, age, and BMI categories where possible.

Both, Spearman and Pearson correlation coefficients were included, depending on which type was provided by the study. The main difference between these two measures is that the Spearman correlation coefficient applies to non-parametric data, whereas the Pearson correlation coefficient requires normally distributed data. In order to make it clear to the reader which coefficient has been used we present $(\rho)$ for Spearman correlations and $(r)$ for Pearson correlations. Reported metrics in this review were derived from the individual studies. Correlations of accelerometer-derived total PA and total measures from questionnaires assessing sedentary behavior were excluded as they are expected to be inversely correlated. Accelerometer wear methods were also extracted. In Additional files 1, 2 and 3, the number of participants is presented along with the brand and/or model of accelerometer used in the investigations, the settings of the accelerometer measurements, the questionnaires used, and the correlations between PA measured by questionnaire accelerometer. Results organized by sex, age and BMI categories are presented sequentially.

\section{Results}

The defined search strategy in PubMed resulted in 556 records (Fig. 1). All abstracts were reviewed and after application of the inclusion and exclusion criteria, 57 investigations remained relevant for this review (Table 1, sorted by publication date). Main exclusion criteria for this manuscript were lack of information on correlations, fewer than 100 participants, age younger than 18 years, and non-English publication (Additional file 4).

Comparisons between questionnaires and accelerometers were reported as Spearman $(\rho)$ or Pearson (r) correlation coefficients as reported in the original manuscripts. In one study, by DeHollander et al. [19], no correlations were reported, instead, percentage of exact agreement and maximum agreement were calculated.

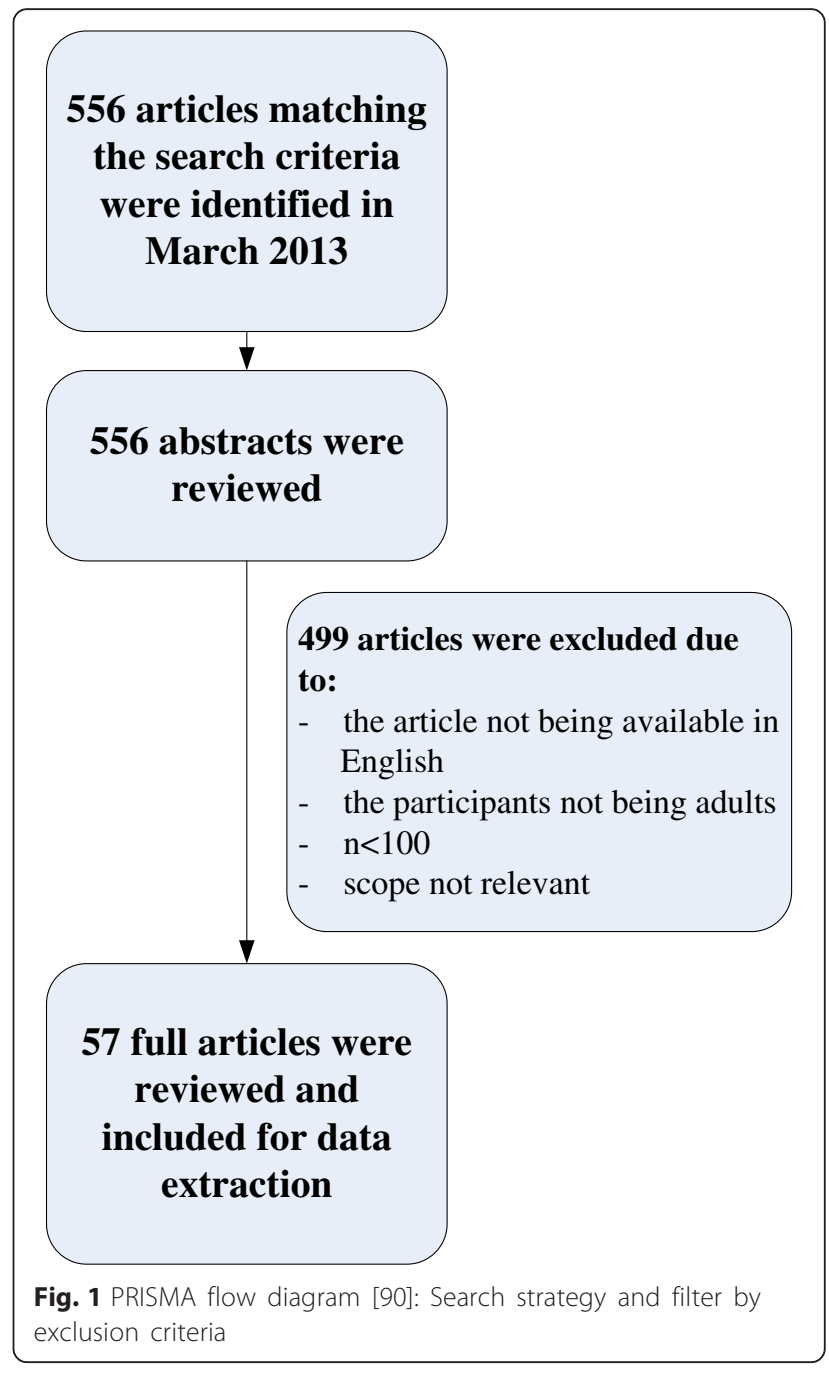

Accelerometer wear methods: wear-time and application In 37 of the 57 reviewed investigations, participants were asked to wear the accelerometers for 7 consecutive days during waking hours [20-56]. Eight investigations asked participants to wear the accelerometers for 4 days $[19,43,57-62]$. In only 4 studies participants were asked to wear the accelerometers for more than 7 days (9 days to four weeks) [63-66]. For the rest of the studies, wear-time ranged between 2 and 6 days [67-72]. In nearly all reviewed studies, participants wore the devices only during waking hours and removed them during water-based activities. Many of the investigations $(n=14)$ required a minimum of 4 valid measurement days per week $[19,29,30,33,35,40,41,45,56-58,65,70,72]$. Nine studies required a wear-time of at least 5 days, and 7 investigations reported various minimum numbers of days ranging between 1 and 7 days [21, 23-28, 34, 36, 38, 39, $44,50,62,66,69]$. Definitions of 'valid days' were available in 28 of the investigations; 23 of these studies required a minimum wear-time of ten hours per day $[21,23,24,26$, 
Table 1 Publications included in this review $(n=57)$

\begin{tabular}{|c|c|}
\hline Author & Journal \\
\hline Sabia & Am J Epidemiol. 2014 Mar 15;179(6):781-90. \\
\hline $\begin{array}{l}\text { Dahl- } \\
\text { Petersen }\end{array}$ & Med Sci Sports Exerc. 2013 Apr;45(4):728-36 \\
\hline $\begin{array}{l}\text { Segura- } \\
\text { Jiménez }\end{array}$ & $\begin{array}{l}\text { Clin Exp Rheumatol. } 2013 \text { Nov-Dec;31 } \\
\text { (6 Suppl 79):S94-101. Epub } 2013 \text { Dec } 2\end{array}$ \\
\hline $\begin{array}{l}\text { Pettee } \\
\text { Gabriel }\end{array}$ & Menopause. Feb 2013; 20(2): 152-161. \\
\hline Warner & Am J Health Behav. Mar 2012; 36(2): 168-178. \\
\hline Hekler & J Phys Act Health. 2012 Feb;9(2):225-36. \\
\hline Kwak & $\begin{array}{l}\text { J Phys Act Health. } 2012 \text { Nov;9(8):1130-7. } \\
\text { Epub } 2011 \text { Dec } 27\end{array}$ \\
\hline Celis-Morales & PLoS ONE 7 (5): e36345. 2012 May 9 \\
\hline Scheers & $\begin{array}{l}\text { Int. Journal of Behavioral Nutrition and } \\
\text { Physical Activity. 9:71. } 2012\end{array}$ \\
\hline Dunton & Front Psychol. 2012; 3: 260. \\
\hline $\begin{array}{l}\text { The InterAct } \\
\text { Consortium }\end{array}$ & Eur J Epidemiol (2012) 27:15-25 \\
\hline Sullivan & Int J Behav Nutr Phys Act. 2012; 9: 13. \\
\hline Grimm & J Aging Phys Act. 2012 Jan;20(1):64-79 \\
\hline Mâsse & J Phys Act Health. 2012 Feb;9(2):237-48 \\
\hline De Hollander & J Clin Epidemiol. 2012;65(1):73-81 \\
\hline Nang & BMC Med Res Methodol. 2011 Oct 13;11:141 \\
\hline Semanik & $\begin{array}{l}\text { Arthritis Care Res (Hoboken) } 2011 \text { Dec; } \\
\text { 63(12):1766-72. doi: 10.1002/acr.20644 }\end{array}$ \\
\hline Lee & $\begin{array}{l}\text { J Community Health. } 2011 \text { Dec;36(6):1011-23. } \\
\text { doi: 10.1007/s10900-011-9403-5. }\end{array}$ \\
\hline Tomioka & $\begin{array}{l}\text { J Epidemiol. } 2011 \text { Nov 5; 21(6):459-65. } \\
\text { Epub } 2011 \text { Sep } 24\end{array}$ \\
\hline Lee & Int J Behav Nutr Phys Act. 2011 Aug 1; 8:81. \\
\hline Peters & Med Sci Sports Exerc. 2010 Dec; 42(12):2222-30. \\
\hline Clark & Med Sci Sports Exerc. 2011 Oct; 43(10):1907-12. \\
\hline Lee & J Community Health; 26 April 2011 \\
\hline Nicaise & $\begin{array}{l}\text { Journal of Physical Activity and Health; 8, } \\
881-890.2011\end{array}$ \\
\hline Emaus & $\begin{array}{l}\text { Scand J Public Health. } 2010 \text { Nov; } 38 \\
\text { (5 Suppl):105-18. }\end{array}$ \\
\hline Hagstromer & J Phys Act Health. 2010 Jul;7(4):541-50 \\
\hline Weikert & $\begin{array}{l}\text { J Neurol Sci. } 2010 \text { Mar 15; 290(1-2):6-11. } \\
\text { Epub } 2010 \text { Jan } 8 .\end{array}$ \\
\hline Hallal & $\begin{array}{l}\text { Journal of Physical Activity \& Health, } \\
2010,7,402-409\end{array}$ \\
\hline $\begin{array}{l}\text { van der } \\
\text { Ploeg }\end{array}$ & $\begin{array}{l}\text { Research Q Exercise Sport, 2010, Vol. 81, } \\
\text { No. 1,97-101 }\end{array}$ \\
\hline Rosenberg & $\begin{array}{l}\text { Journal of Physical Activity and Health, } \\
2010,7,697-705\end{array}$ \\
\hline Wollmerstedt & J Arthroplasty. 2010 Apr;25(3):475-480 \\
\hline Evenson & $\begin{array}{l}\text { Intl Journal of Behavioral Nutrition and } \\
\text { Physical Activity. 2010. 7:21 }\end{array}$ \\
\hline Li & $\begin{array}{l}\text { Eur J Clin Nutr. } 2009 \text { Dec; 63(12):1448-51. } \\
\text { Epub } 2009 \text { Jul } 29 .\end{array}$ \\
\hline
\end{tabular}

Table 1 Publications included in this review $(n=57)$ (Continued)

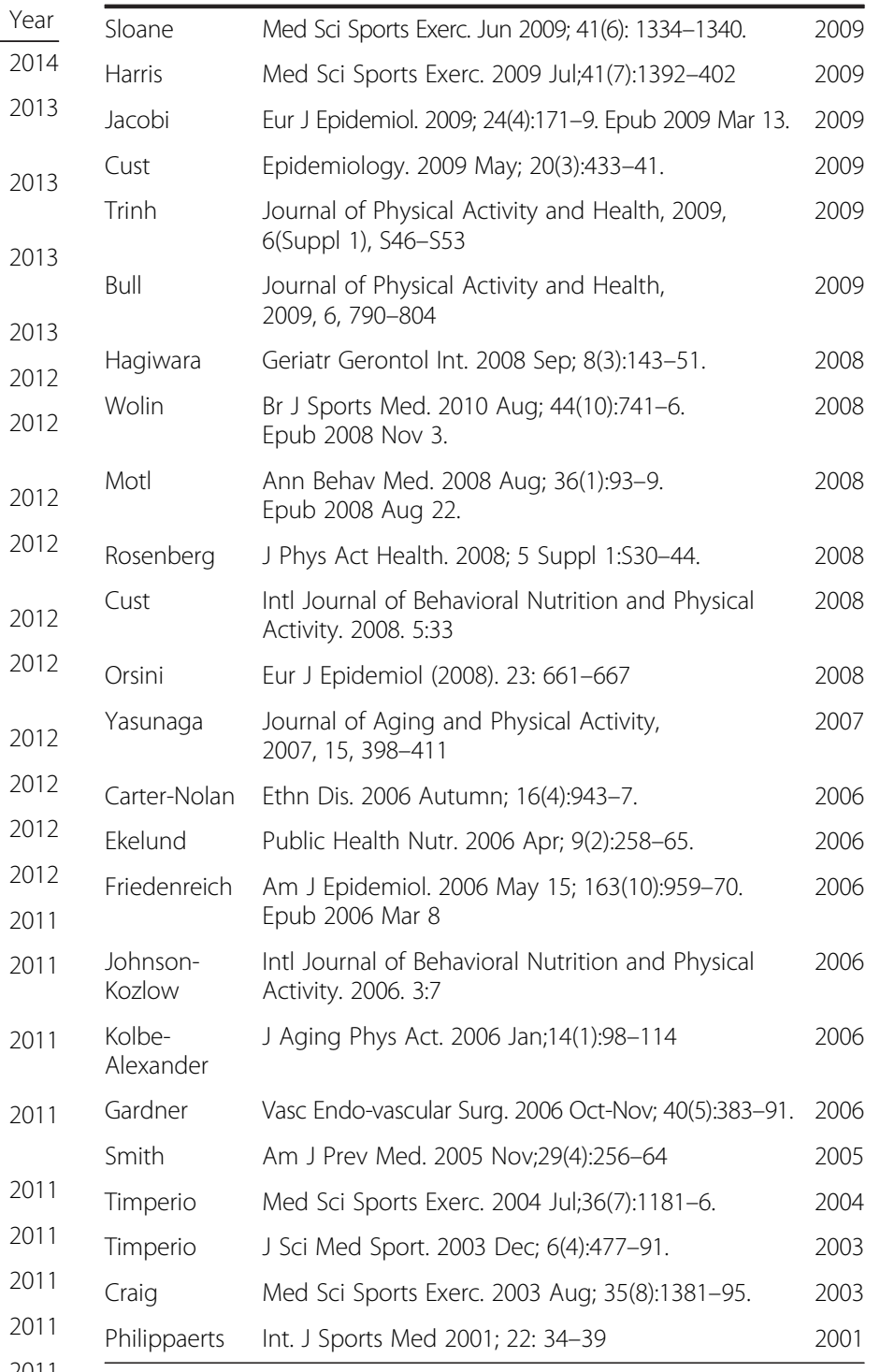

$27,30,31,33,34,36,38-41,43-45,47,50,56,57,69,70$, 2010 72], one deemed eight hours per day to be sufficient for the day to be valid [29], one $22 \mathrm{~h}$ per day [68], one $16 \mathrm{~h}$ [65] and 2 others even $24 \mathrm{~h}[19,50]$. Spearman correla2010 tions tended to be stronger with increased wear-time (over 7 days). When wear-time accounted for at least 14 days, 2010 correlations ranged from $\rho=0.41$ to $\rho=0.53[63,64]$. One exception were the results from the investigation conducted by Gardner et al. [67] where wear-time was only 2 consecutive days and Pearson's correlation between the questionnaire and accelerometry was reported as $r=0.71$.

In almost all investigations which reported the placement of the accelerometer participants wore the devices attached to an elastic belt. One study preferred attachment with a clip, but provided waist belts in case the clip attachment was not possible [70]. Of the studies that specified the placement of accelerometers, 17 reported 
attachment on the hip [20, 28, 30, 31, 33-35, 39, 46-50, $57,64,69,70,72]$ and 6 studies reported attachment around the waist [29, 32, 39, 43, 60, 73]. Chest [58], iliac crest [35], wrist [65] and triceps [68] were also reported attachment sites.

The 57 studies reviewed investigated correlations of questionnaire-derived PA measures with accelerometryderived PA measures. Many investigations used the International Physical Activity Questionnaire (IPAQ), however, there was still a great diversity of questionnaires used in the different studies. Most of the reviewed studies used an Actigraph (formerly known as MTI/CSA) monitor. Overall correlations for total PA ranged from $r=0.14(P<0.001)$ [52] to $r=0.58(P<0.001)$ [69]. Of the reviewed studies only one third reported correlations $\geq 0.40$.

Gender comparisons were available in 25 of the included studies (Additional file 1) [20, 22, 24, 27, 29, 31, 39, 42, 43, $45,47-49,52,53,56,57,61,62,64,65,69-71,73]$ and seven were limited specifically to women $[22,45,49,50$, $53,66,74]$. Correlations of total questionnaire scores with total accelerometer measures ranged from $\rho=0.08$ (n.s.) [31] to $r=0.58(P<0.001)$ [70] for men and from $r=-0.02$ (n.s.) [71] to $\rho=0.49(P<0.01)$ [64] for women. Of the 21 studies that reported correlations by gender, most investigated associations for moderate and vigorous intensity PA. For moderate PA data from questionnaires and accelerometers, correlations ranged from $r=0.03$ (n.s.) [29] to $r=$ $0.40(P<0.01)[20,47]$ for men and from $r=-0.02$ (n.s.) [53] to $r=0.29(P=0.02)$ [47] for women. Correlations for vigorous PA ranged from $\mathrm{r}=-0.15$ (n.s.) [29] to $r=0.43$ $(P=0.05)$ [47] for men and from $r=-0.36(P<0.05)$ [20] to $r=0.52(P<0.001)$ [20] for women. Associations for moderate-to-vigorous intensity PA among men and/or women were examined by 6 investigations $[20,31,42$, $48,49,57$ ] and ranged from $\rho=0.04$ (n.s.) [31] to $r=$ $0.44(P<0.01)$ [48] for men and from $\rho=0.01$ (n.s.) [57] to $r=0.39(P<0.01)$ [20] for women. Emaus et al. [31] and Sullivan et al. [57] reported correlations for light PA between $\rho=-0.23(P<0.05)$ and $\rho=0.29(P<0.01)$ among men and $\rho=-0.22 \quad(P<0.05)$ and $\rho=0.45 \quad(P<0.05)$ among women. Within the individual studies, associations between measured and reported PA tended to be stronger among men than among women (Fig. 2).

Six studies investigated PA correlations distinguished by BMI categories (Additional file 2) [20, 24, 41, 43, 52, 72]. There were no consistently defined cut points for BMI among the 6 investigations. Cust et al. [41] used median BMI as cut point $<27.2 \mathrm{~kg} / \mathrm{m}^{2}$ and $\geq 27.2 \mathrm{~kg} / \mathrm{m}^{2}$. Association of PA assessed by questionnaire and measured by accelerometer were stronger for the lower BMI group, although differences were not statistically significant. Lee et al. [43] and Friedenreich et al. [24] set the cut points to $<25 \mathrm{~kg} /$ $\mathrm{m}^{2}$ and $\geq 25 \mathrm{~kg} / \mathrm{m}^{2}$ which is defined as the standard by the WHO for distinguishing overweight/obese from normal-/underweight individuals [75]. Correlations ranged from $\rho=0.09(P<0.01$, moderate intensity PA) [43] to $r=0.38(P<0.05$, total PA) [24] for the group with lower BMI and from $\rho=0.10$ (n.s., moderate intensity PA) to $\rho=0.22(P<0.001$, vigorous intensity PA) [43] for the group with higher BMI. Warner et al. [72] and Kwak et al. [52] set their cut points to $<25 \mathrm{~kg} / \mathrm{m}^{2}$ (normal), $\geq 25-<$ $30 \mathrm{~kg} / \mathrm{m}^{2}$ (overweight) and $\geq 30 \mathrm{~kg} / \mathrm{m}^{2}$ (obese). Whereas Warner et al. observed the strongest correlations between questionnaire-derived total PA and accelerometry among overweight participants $(r=0.55, P=0.003)$, Kwak et al. noted the strongest correlations regarding work-related PA among normal weight participants $(r=0.46, P<0.01)$. The results from Lee et al.[43] showed stronger, yet statistically non-significant, correlations for participants with a BMI $\geq 25 \mathrm{~kg} / \mathrm{m}^{2}$ whereas Friedenreich et al. [24] reported stronger associations for the group with lower BMI (BMI $<25 \mathrm{~kg} / \mathrm{m}^{2}$ ). Timperio et al. [20] set the cut points for BMI to $\leq 25 \mathrm{~kg} / \mathrm{m}^{2}$ and $>25 \mathrm{~kg} / \mathrm{m}^{2}$ and also stratified results by gender. Among participants with a

\section{Correlations of PA among men and women}

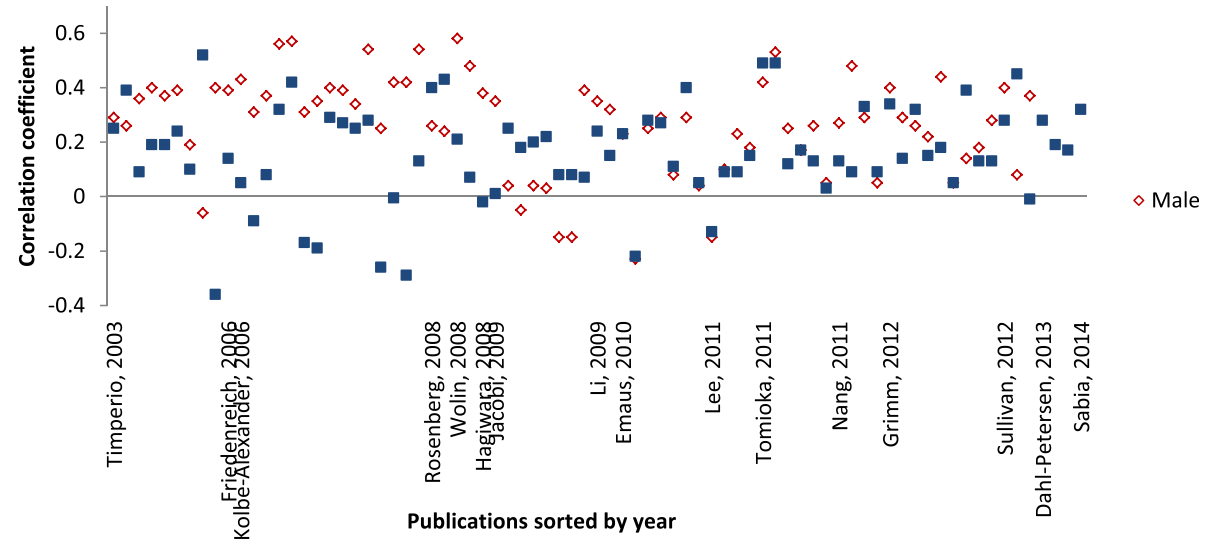

Fig. 2 Correlations among men and women within the individual studies 
BMI $\leq 25 \mathrm{~kg} / \mathrm{m}^{2}$ correlations ranged from $r=-0.06$ (n.s., men) for intensities of $\geq 6$ METs to $r=0.52(P \leq 0.001$, women) for intensities of $\geq 6$ METs. Correlations among participants with a BMI $>25 \mathrm{~kg} / \mathrm{m}^{2}$ ranged from $r=-0.36$ $(P<0.05$, women) to $r=0.40(P<0.05$, men). Overall, no consistent results according to BMI could be identified in these four studies.

Regarding age of participants, only the results of 17 studies could be compared due to differences in setting the cut points for age. For this review, a cut point of 65 years of age was chosen in order to capture the greatest possible amount of studies. The age of 65 years is also a generally accepted cut point in developed countries to distinguish between the elderly and the younger, commonly working population.

Results from eleven investigations could be summarized for participants $\leq 65$ years of age (Additional file 3 ) $[21,24,30,35,36,41,43,44,59,65,68,69]$. Correlations ranged from $\rho=0.04$ (n.s.) [43] to $r=0.47(P<0.001)$ [59] for total PA. For moderate intensity, correlations between PA assessed by questionnaire and accelerometry ranged from $r=0.01$ (n.s.) to $\rho=0.35$ (95\% CI $=0.08$ 0.55 ) [30], and for vigorous intensity, correlations ranged from $r=-0.03$ (n.s.) [36] to $r=0.83(P<0.05)$ [69]. Two studies also reported associations for moderate-tovigorous PA [30, 36]. The weakest association was $r=0.09$ (n.s.) and the strongest was $r=0.30(95 \% \mathrm{CI}=0.09-0.49)$. Five studies reported results for the elderly of $\geq 65$ years of age $[28,63-65,71]$. Correlations ranged from $r=0.16$ $(P=0.02)$ to $r=0.53(P<0.01)$ for total PA. Tomioka et al. [64] also reported correlations for vigorous and moderate PA. For vigorous intensity, the weakest association was seen among women from 65 to 74 years of age $[\rho=0.12$ (n.s.) $]$ and the strongest was seen among men from 65 to 74 years of age $(\rho=0.25, P<0.05)$. For moderate PA the weakest correlation was $\rho=0.03$ (n.s.) among women from 75 to 89 years of age and the strongest was $\rho=0.26(P<0.05)$ among men from 65 to 74 years of age. Yasunaga et al. [63] assessed associations for moderate-to-vigorous and light PA among the elderly ( $\geq 65$ years of age), with correlation coefficients of $r=0.53$ (n.s.) and $r=0.28$ (n.s.), respectively. Although these results showed no consistency among age groups, correlations within the individual studies tended to be slightly higher for younger age groups.

\section{Discussion}

This review identified 57 publications that compared PA questionnaires with accelerometry data. Although there have been a few systematic reviews discussing self-reported versus objective PA $[17,18]$, the present work is novel both in its subgroup assessment as well as in its framing of accelerometer wear methods. Today there are no set standards for use of accelerometers with respect to wear-time, minimal wearing time to be considered valid, or position of application, even though there seem to be trends for each of these aforementioned elements. Large observational studies, such as the National Health and Nutrition Examination Survey (NHANES) study have changed their protocols from attachment on hips to wrists [76]. Some studies suggest that hip-worn accelerometers assess PA more precisely compared to wrist-worn devices [77] whereas other investigations reported reasonable precise estimations of PA when using wrist-worn devices [78, 79]. However, to some extent wear methods are dependent on the study aim, the design of the accelerometers or the activity that is aimed to be captured, as well as acceptability within the study population. Of the 57 studies reviewed, accelerometer wear-time of 7 consecutive days during waking hours was the most consistently reported duration of measurement $(N=37,65 \%)$. Further requirements included having at least four out of 7 valid days (14 out of 37 studies), which was defined in most investigations, as being worn for at least $10 \mathrm{~h}$. Many studies included at least one weekend day of the required wear-period. Since correlations seemed to be stronger with increased wear-time one could consider longer accelerometer wear-time for future studies. Additionally, in previous studies it could be shown that altering wear time led to significant differences in adherence as well as PA measures [12,13]. It is important to note that in this review wear-time information was investigated only in the 57 included studies, and not in all available studies using accelerometry. Nevertheless, the identified inconsistencies in wear-time requirement within the 57 investigations demonstrate the need for general guidelines for the use of accelerometers in free-living conditions in order to increase comparability of these and future studies.

It has been shown that healthy, younger, unemployed and smoking participants are less likely to be compliant regarding wearing-time of accelerometers while participants that are suffering from a serious disease may be more interested in participating in research and thus may be more compliant.

Investigations reviewed in this manuscript compared PA scores of questionnaires with PA measures from accelerometers. In the 57 investigations, correlations between questionnaires and accelerometry were weak to moderate. This finding is in agreement with previous reviews $[80,81]$. Potential explanations for this result might be associated with the advantages and disadvantages of both methods. Questionnaires can assess all types of PA, including stationary activities such as weight lifting. They can also cover long time frames. However, due to the complex and subjective nature of the gathered information, they may be subject to limitations in recollection or to recall bias, such as estimating or recalling the incorrect intensity $[5,6,82]$. Alternatively, accelerometers assess PA continuously and objectively. Unlike questionnaires, they are not suitable for 
long-term measurements and thus seasonable activities can be captured only through repeated administration. This is expected to reduce correlations. There are further aspects that limit PA measurement by accelerometry, such as the devices not being able to cover stationary activities, strength training, or cycling. Water-based activities can also lead to misclassifications in individual PA measurement in cases where the sensors are not waterproof or not worn during that activity. In addition, the wearing of an accelerometer itself may promote PA [16].

Data retrieved from accelerometers are commonly expressed as "counts". This non-dimensional unit cannot be meaningfully interpreted, and therefore there exists the need to convert counts to an informative measure of PA, such as METs or kilocalories (kcals). With the help of regression equations, accelerometer counts are translated into measures of energy expenditure and measured PA can be classified into different intensities. There are many different regression equations reported, and depending on which accelerometer was used to determine the amount and intensity of PA, correlations with questionnaires vary, as different data processing algorithms result in different values of PA outcome measures [10]. Bassett et al. [83] reported that accelerometers may over-predict energy expenditure during walking while they may under-predict energy expenditure of many other activities. In the 57 studies, accelerometry data was reported as MET scores, time spent in physical activities, accelerometer counts per minute, or step counts. Questionnaire data was also reported in various measures (e.g., minutes per day, hours per week). This variation limits the ability to compare results across studies. Data processing guidelines for accelerometry would allow comparability among studies.

Among 25 studies, vigorous activity was more strongly correlated with self-report in men than in women ((e.g., $r=0.43,(P<0.05)$ men vs. $r=0.05$, (n.s.) women [47] or $\rho=0.23, P<0.001$ men; $\rho=0.09, P<0.05$ women [43])). This could be explained by the fact that men have higher levels of vigorous PA [24, 84], which is more easily assessed by questionnaires. Women tend to engage more in light PA, which is the most challenging type of activity to recall because it is most dominant in daily life as, for example, in household activities [24]. Correlations for light physical activities were investigated by Emaus et al. [31]. They showed negative correlations for self-reported and objectively measured leisure activities with light PA among both men and women $(\rho=-0.23, P<0.05$ and $\rho=-0.22, P<0.05)$, whereas weak to moderate correlations were reported for work activities $(\rho=0.29, P<0.01$ men and $\rho=0.40, P<0.001$ women).

Only 6 studies investigated PA correlations by BMI categories and of those, there were small differences in defining the BMI categories, thus making comparison across studies challenging. The four investigations presented their results in different manners concerning BMI categories as well as different PA intensity categories. This inconsistency, once again, shows the importance of general guidelines to enable a reasonable comparison across studies like this.

Although there were no conclusive findings suggesting stronger associations by age group ( $<65$ years vs. $\geq 65$ years) correlations tended to be slightly higher among participants in the younger groups. Notably, most PA questionnaires are designed for younger populations; the focus of these studies is more on sports and recreational activities and therefore, do not meet the criteria for the elderly.[85] Kowalski et al. investigated the agreement between objective and self-reported PA in older adults and found generally weak to moderate correlations $(r=-0.02-0.79)$ [17]. Older people are more likely to engage in activities that are most inaccurately assessed by questionnaires [7]. This might be an explanation for the slightly weaker correlations among the elderly reported here.

While studies assessing the correlations between questionnaire and accelerometer data are the primary focus of this review, an alternative method to assess agreement between two quantitative measurements are BlandAltman plots [86]. Prior research has shown that bias in questionnaires can be revealed by Bland-Altman plots, while it may remain undetected by the use of correlation coefficients [87]. Therefore, studies using this graphical method may provide additional valuable insights [88]. Of the 57 studies presented in this review 18 utilized BlandAltman plots to evaluate agreement between the mean differences of questionnaire and accelerometer data [21, $23,28,35,36,40,42,47,51,52,56,57,60,62,68-70$, $73]$. We present the results of two studies exemplary. Interested readers are advised to consult the references provided above. Dahl-Petersen and colleagues [62] reported the results of Bland-Altman agreement methods and correlation coefficients. They observed moderate validity for questionnaire-based overall PA from the IPAQ compared to accelerometer data $(r=0.20-0.35, \quad P<0.01)$. BlandAltman agreement analyses showed relatively small median differences for all measures of PA; however, moderateintensity PA was substantially greater when reported by IPAQ when including walking [62]. Similarly, a study in an Asian population [69] showed a higher estimate of selfreported PA using the IPAQ compared to accelerometer data. These examples illustrate that, beyond correlation coefficients the Bland-Altman method provides additional information on the agreement between questionnaires and accelerometers.

The strength of this review is the inclusion of more than 50 studies with at least 100 participants which results in increased stability of observed associations. However, the varying measurement conditions and 
methods complicate comparison of findings from different studies. The reported accelerometry metrics in this review are derived from the individual studies and thus can differ. Questionnaires that assess PA are variable, with differences in number of items, time frame, focus, or background and characteristics of study population, which further complicates comparisons among different studies. A further limitation is that information on the exclusion of PA bouts of less than $10 \mathrm{~min}$, which can have a significant effect on the correlations, was not always available. In this review, only the available correlational information from each investigation was used to compare results from the 57 studies in order to facilitate comparison among all reviewed studies. However, there are also other well-established methods to demonstrate associations (e.g., regression). Furthermore, due to the minimum number of required participants for inclusion into this review, most studies included healthy participants from the general population.

Only eight studies included participants with breast or prostate cancer, arterial diseases, multiple sclerosis, fibromyalgia, total hip arthroplasty, or rheumatoid/ osteoarthritis [26, 32, 33, 67, 73, 89]. PA plays a significant role in the prevention or progression of different diseases [1]. This fact illustrates the importance of continued research of PA not only in healthy populations, but particularly in diseased cohorts in order to establish guidelines for patients or their physicians; Patients diagnosed with a disease such as cancer are often motivated to modify their lifestyles [15].

This review highlights the need for further research on the assessment of PA in studies. Due to the inconsistent correlations, the different aspects measured by questionnaires and accelerometers and some differences in the dimensions studied, future investigations should ideally use both questionnaires and accelerometers to gain the most accurate possible and complementary information. Needed are also guidelines for accelerometer settings, data processing and wear methods and the summaries presented in this review may help foster these. As reported in this review there were only a few studies investigating PA in diseased populations. Due to the importance of PA in the prevention of many diseases, such as cancer, more investigations relating to PA assessment in diseased populations are needed.

\section{Conclusion}

There were no clear patterns in correlations between PA questionnaires and accelerometry by gender, age, BMI, or wear time. However, correlations seemed to be slightly stronger among men compared to women and younger vs. older populations. Due to differences in the dimensions studied by each method, it is advised that studies use both questionnaires and accelerometers to gain the most complete information. Furthermore, due to the low number of studies in patient groups, continued research to identify the best combination of wear methods is needed.

\section{Additional files}

Additional file 1: Summary of correlations of physical activity data assessed
by questionnaires and accelerometers with respect to gender. (PDF $179 \mathrm{~kb}$ )

Additional file 2: Summary of correlations of physical activity data assessed by questionnaires and accelerometers with respect to BMI. (PDF 183 kb)

Additional file 3: Summary of correlations of physical activity data assessed by questionnaires and accelerometers with respect to age. (PDF $263 \mathrm{~kb}$ )

Additional file 4: PRISMA checklist [90]. (DOC 62 kb)

\section{Abbreviations}

BMI, body mass index; DLW, doubly labeled water; GPAQ, Global Physical Activity Questionnaire; HRM, heart rate monitors; IPAQ, International Physical Activity Questionnaire; kcal, kilocalories; MET, metabolic equivalent of tasks; NHANES, National Health and Nutrition Examination Survey; PA, physical activity; WHO, World Health Organization

\section{Acknowledgements}

We would like to thank Dr. Petra Schrotz-King for critically revising the manuscript.

\section{Funding}

Cornelia M. Ulrich and Jennifer Ose received funding from the Huntsman Cancer Foundation.

\section{Availability of data and materials}

Not applicable.

\section{Authors' contributions}

SS was involved in the concept and design, data acquisition, data analysis and interpretation. JO critically revised the manuscript and led submission. JCC has revised the manuscript and was involved in data analysis and interpretation. MP and BB were involved in data acquisition. ES and KS revised the manuscript and were involved in data analysis and interpretation. CMU is SS's supervisor, revised the manuscript and was involved in the concept and design, data analysis and interpretation. All authors read and approved the final manuscript.

\section{Competing interests}

The authors declare that they have no competing interests.

\section{Consent for publication}

Not applicable.

\section{Ethics approval and consent to participate} Not applicable.

\section{Author details}

${ }^{1}$ Division of Preventive Oncology, National Center for Tumor Diseases (NCT), Im Neuenheimer Feld 460, 69120 Heidelberg, Germany. ${ }^{2}$ Division of Preventive Oncology, German Cancer Research Center (DKFZ), Im Neuenheimer Feld 460, 69120 Heidelberg, Germany. ${ }^{3}$ Division of Clinical Epidemiology, German Cancer Research Center (DKFZ), Im Neuenheimer Feld 581, 69120 Heidelberg, Germany. ${ }^{4}$ Department of Cancer Epidemiology, $\mathrm{H}$. Lee Moffitt Cancer Center and Research Institute, 12902 Magnolia Drive, Tampa, FL 33612, USA. ${ }^{5}$ Unit of Environmental Epidemiology, German Cancer Research Center (DKFZ), Im Neuenheimer Feld 581, 69120 Heidelberg, Germany. ${ }^{6}$ Department of Population Health Sciences, University of Utah, Williams Building, 295 Chipeta Way, Salt Lake City, UT 84108, USA.

${ }^{7}$ Population Sciences, Huntsman Cancer Institute, University of Utah, Circle of Hope Dr. 2000, Room 4165, Salt Lake City, UT 84112, USA. 


\section{Received: 2 February 2016 Accepted: 30 May 2016}

Published online: 16 June 2016

\section{References}

1. World Health Organization. Global recommendations on physical activity for health. Geneva: World Health Organization; 2010

2. Caspersen CJ, Powell KE, Christenson GM. Physical activity, exercise, and physical fitness: definitions and distinctions for health-related research. Public Health Rep. 1985;100:126-31.

3. National Institutes of Health. Types of Physical Activity. 2011.

4. Chu AH, Ng SH, Koh D, Muller-Riemenschneider F. Reliability and Validity of the Self- and Interviewer-Administered Versions of the Global Physical Activity Questionnaire (GPAQ). PLoS One. 2015;10:e0136944.

5. Ferrari $P$, Friedenreich $C$, Matthews $C E$. The role of measurement error in estimating levels of physical activity. Am J Epidemiol. 2007;166:832-40.

6. Neilson HK, Robson PJ, Friedenreich CM, Csizmadi I. Estimating activity energy expenditure: how valid are physical activity questionnaires? Am J Clin Nutr. 2008:87:279-91.

7. Washburn RA, Jette AM, Janney CA. Using Age-Neutral Physical Activity Questionnaires in Research with the Elderly. J Aging Health. 1990;2:341-56.

8. Troiano RP. A timely meeting: objective measurement of physical activity. Med Sci Sports Exerc. 2005;37:S487-489.

9. Westerterp KR. Physical activity assessment with accelerometers. Int J Obes Relat Metab Disord. 1999:23 Suppl 3:S45-49.

10. Heil DP, Brage S, Rothney MP. Modeling physical activity outcomes from wearable monitors. Med Sci Sports Exerc. 2012;44:S50-60.

11. Matthews CE, Hagstromer M, Pober DM, Bowles HR. Best practices for using physical activity monitors in population-based research. Med Sci Sports Exerc. 2012:44:568-76.

12. Herrmann SD, Barreira TV, Kang M, Ainsworth BE. Impact of accelerometer wear time on physical activity data: a NHANES semisimulation data approach. Br J Sports Med. 2014;48:278-82.

13. Colley R, Connor Gorber S, Tremblay MS. Quality control and data reduction procedures for accelerometry-derived measures of physical activity. Health Rep. 2010;21:63-9.

14. Roth MA, Mindell JS. Who provides accelerometry data? Correlates of adherence to wearing an accelerometry motion sensor: the 2008 Health Survey for England. J Phys Act Health. 2013;10:70-8.

15. Patterson RE, Neuhouser ML, Hedderson MM, et al. Changes in diet, physical activity, and supplement use among adults diagnosed with cancer. J Am Diet Assoc. 2003;103:323-8.

16. Skender S, Schrotz-King P, Bohm J, et al. Repeat physical activity measurement by accelerometry among colorectal cancer patients-feasibility and minimal number of days of monitoring. BMC Res Notes. 2015:8:222

17. Kowalski K, Rhodes R, Naylor PJ, et al. Direct and indirect measurement of physical activity in older adults: a systematic review of the literature. Int J Behav Nutr Phys Act. 2012;9:148.

18. Prince $S A$, Adamo KB, Hamel ME, et al. A comparison of direct versus selfreport measures for assessing physical activity in adults: a systematic review. Int J Behav Nutr Phys Act. 2008;5:56

19. de Hollander EL, Zwart L, de Vries SI, Wendel-Vos W. The SQUASH was a more valid tool than the OBiN for categorizing adults according to the Dutch physical activity and the combined guideline. J Clin Epidemiol. 2012;65:73-81

20. Timperio A, Salmon J, Crawford D. Validity and reliability of a physical activity recall instrument among overweight and non-overweight men and women. J Sci Med Sport. 2003;6:477-91.

21. Craig $C L$, Marshall $A L$, Sjostrom M, et al. International physical activity questionnaire: 12-country reliability and validity. Med Sci Sports Exerc. 2003;35:1381-95.

22. Carter-Nolan PL, Adams-Campbell LL, Makambi K, et al. Validation of physical activity instruments: Black Women's Health Study. Ethn Dis. 2006;16:943-7.

23. Ekelund U, Sepp H, Brage S, et al. Criterion-related validity of the last 7-day, short form of the International Physical Activity Questionnaire in Swedish adults. Public Health Nutr. 2006;9:258-65.

24. Friedenreich CM, Courneya KS, Neilson HK, et al. Reliability and validity of the Past Year Total Physical Activity Questionnaire. Am J Epidemiol. 2006; 163:959-70.

25. Smith BJ, Marshall AL, Huang N. Screening for physical activity in family practice: evaluation of two brief assessment tools. Am J Prev Med. 2005;29:256-64
26. Motl RW, McAuley E, Snook EM, Gliottoni RC. Does the relationship between physical activity and quality of life differ based on generic versus diseasetargeted instruments? Ann Behav Med. 2008;36:93-9.

27. Rosenberg DE, Bull FC, Marshall AL, et al. Assessment of sedentary behavior with the International Physical Activity Questionnaire. J Phys Act Health. 2008:5 Suppl 1:S30-44.

28. Harris TJ, Owen CG, Victor CR, et al. A comparison of questionnaire, accelerometer, and pedometer: measures in older people. Med Sci Sports Exerc. 2009:41:1392-402

29. Jacobi D, Charles MA, Tafflet M, et al. Relationships of self-reported physical activity domains with accelerometry recordings in French adults. Eur J Epidemiol. 2009;24:171-9.

30. Cust AE, Armstrong BK, Smith BJ, et al. Self-reported confidence in recall as a predictor of validity and repeatability of physical activity questionnaire data. Epidemiology. 2009:20:433-41.

31. Emaus A, Degerstrom J, Wilsgaard T, et al. Does a variation in self-reported physical activity reflect variation in objectively measured physical activity, resting heart rate, and physical fitness? Results from the Tromso study. Scand J Public Health. 2010:38:105-18.

32. Weikert M, Motl RW, Suh Y, et al. Accelerometry in persons with multiple sclerosis: measurement of physical activity or walking mobility? J Neurol Sci. 2010;290:6-11.

33. Semanik P, Lee J, Manheim L, et al. Relationship between accelerometerbased measures of physical activity and the Yale Physical Activity Survey in adults with arthritis. Arthritis Care Res (Hoboken). 2011;63:1766-72.

34. Peters TM, Shu XO, Moore SC, et al. Validity of a physical activity questionnaire in Shanghai. Med Sci Sports Exerc. 2010;42:2222-30.

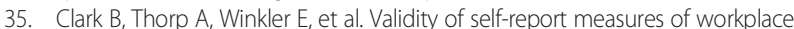
sitting time and breaks in sitting time. Med Sci Sports Exerc. 201 1;43:1907-12

36. Trinh OT, Nguyen ND, van der Ploeg HP, et al. Test-retest repeatability and relative validity of the Global Physical Activity Questionnaire in a developing country context. J Phys Act Health. 2009:6 Suppl 1:\$46-53.

37. Bull FC, Maslin TS, Armstrong T. Global physical activity questionnaire (GPAQ): nine country reliability and validity study. J Phys Act Health. 2009:6:790-804.

38. van der Ploeg HP, Tudor-Locke $C$, Marshall AL, et al. Reliability and validity of the international physical activity questionnaire for assessing walking. Res Q Exerc Sport. 2010;81:97-101.

39. Rosenberg DE, Norman GJ, Wagner N, et al. Reliability and validity of the Sedentary Behavior Questionnaire (SBQ) for adults. J Phys Act Health. 2010;7:697-705

40. Celis-Morales CA, Perez-Bravo F, Ibanez L, et al. Objective vs. self-reported physical activity and sedentary time: effects of measurement method on relationships with risk biomarkers. PLOS One 2012:7:e36345.

41. Cust AE, Smith BJ, Chau J, et al. Validity and repeatability of the EPIC physical activity questionnaire: a validation study using accelerometers as an objective measure. Int J Behav Nutr Phys Act. 2008;5:33.

42. Evenson KR, Wen F. Measuring physical activity among pregnant women using a structured one-week recall questionnaire: evidence for validity and reliability. Int J Behav Nutr Phys Act. 2010;7:21.

43. Lee PH, Yu YY, McDowell I, et al. Performance of the international physical activity questionnaire (short form) in subgroups of the Hong Kong chinese population. Int J Behav Nutr Phys Act. 2011:8:81.

44. Nicaise V, Marshall S, Ainsworth BE. Domain-specific physical activity and self-report bias among low-income Latinas living in San Diego County. J Phys Act Health. 2011:8:881-90.

45. Orsini N, Bellocco R, Bottai M, et al. Validity of self-reported total physical activity questionnaire among older women. Eur J Epidemiol. 2008;23:661-7.

46. Dunton GF, Liao Y, Kawabata K, Intille S. Momentary assessment of adults' physical activity and sedentary behavior: feasibility and validity. Front Psychol. 2012;3:260.

47. Kolbe-Alexander TL, Lambert EV, Harkins JB, Ekelund U. Comparison of two methods of measuring physical activity in South African older adults. J Aging Phys Act. 2006;14:98-114.

48. Grimm EK, Swartz AM, Hart T, et al. Comparison of the IPAQ-Short Form and accelerometry predictions of physical activity in older adults. J Aging Phys Act. 2012;20:64-79.

49. Masse LC, Fulton JE, Watson KB, et al. Comparing the validity of 2 physical activity questionnaire formats in African-American and Hispanic women. J Phys Act Health. 2012;9:237-48.

50. Gabriel KP, Matthews KA, Perez A et al Self-reported and accelerometerderived physical activity levels and coronary artery calcification progression 
in older women: results from the Healthy Women Study. Menopause. 2013;20:152-61.

51. Hekler EB, Buman MP, Haskell WL, et al. Reliability and validity of CHAMPS self-reported sedentary-to-vigorous intensity physical activity in older adults. J Phys Act Health. 2012;9:225-36.

52. Kwak L, Hagstromer M, Sjostrom M. Can the IPAQ-long be used to assess occupational physical activity? J Phys Act Health. 2012;9:1130-7.

53. Lee RE, Mama SK, Medina AV, et al. Multiple measures of physical activity, dietary habits and weight status in African American and Hispanic or Latina women. J Community Health. 2011;36:1011-23.

54. Sloane R, Snyder DC, Demark-Wahnefried W, et al. Comparing the 7-day physical activity recall with a triaxial accelerometer for measuring time in exercise. Med Sci Sports Exerc. 2009;41:1334-40.

55. Timperio A, Salmon J, Rosenberg M, Bull FC. Do logbooks influence recall of physical activity in validation studies? Med Sci Sports Exerc. 2004;36:1181-6.

56. Hagstromer M, Ainsworth BE, Oja P, Sjostrom M. Comparison of a subjective and an objective measure of physical activity in a population sample. J Phys Act Health. 2010;7:541-50.

57. Sullivan R, Kinra S, Ekelund $U$, et al. Evaluation of the Indian Migration Study Physical Activity Questionnaire (IMS-PAQ): a cross-sectional study. Int J Behav Nutr Phys Act. 2012;9:13.

58. Harmon DL, McMaster D, Shields DC, et al. MTHFR thermolabile genotype frequencies and longevity in Northern Ireland [letter]. Atherosclerosis. 1997; 131:137-8.

59. Philippaerts RM, Westerterp KR, Lefevre J. Comparison of two questionnaires with a tri-axial accelerometer to assess physical activity patterns. Int J Sports Med. 2001:22:34-9.

60. Hallal PC, Simoes E, Reichert FF, et al. Validity and reliability of the telephone-administered international physical activity questionnaire in Brazil. J Phys Act Health. 2010;7:402-9.

61. Li C, Aronsson CA, Hedblad B, et al. Ability of physical activity measurements to assess health-related risks. Eur J Clin Nutr. 2009:63:1448-51.

62. Dahl-Petersen IK, Hansen AW, Bjerregaard $P$, et al. Validity of the international physical activity questionnaire in the arctic. Med Sci Sports Exerc. 2013;45:728-36.

63. Yasunaga A, Park H, Watanabe $\mathrm{E}$, et al. Development and evaluation of the physical activity questionnaire for elderly Japanese: the Nakanojo study. J Aging Phys Act. 2007;15:398-411.

64. Tomioka K, Iwamoto J, Saeki K, Okamoto N. Reliability and validity of the International Physical Activity Questionnaire (IPAQ) in elderly adults: the Fujiwara-kyo Study. J Epidemiol. 2011;21:459-65.

65. Sabia S, van Hees VT, Shipley MJ, et al. Association between questionnaireand accelerometer-assessed physical activity: the role of sociodemographic factors. Am J Epidemiol. 2014;179:781-90.

66. Segura-Jimenez V, Munguia-Izquierdo D, Camiletti-Moiron D, et al. Comparison of the International Physical Activity Questionnaire (IPAQ) with a multi-sensor armband accelerometer in women with fibromyalgia: the al-Andalus project Clin Exp Rheumatol. 2013;31:S94-101.

67. Gardner AW, Montgomery PS. The Baltimore activity scale for intermittent claudication: a validation study. Vasc Endovascular Surg. 2006;40:383-91.

68. Scheers T, Philippaerts R, Lefevre J. Assessment of physical activity and inactivity in multiple domains of daily life: a comparison between a computerized questionnaire and the SenseWear Armband complemented with an electronic diary. Int J Behav Nutr Phys Act. 2012;9:71.

69. Nang EE, Gitau Ngunjiri SA, Wu Y, et al. Validity of the International Physical Activity Questionnaire and the Singapore Prospective Study Program physical activity questionnaire in a multiethnic urban Asian population. BMC Med Res Methodol. 2011;11:141.

70. Wolin KY, Heil DP, Askew S, et al. Validation of the International Physical Activity Questionnaire-Short among Blacks. J Phys Act Health. 2008;5:746-60.

71. Hagiwara A, Ito N, Sawai K, Kazuma K. Validity and reliability of the Physical Activity Scale for the Elderly (PASE) in Japanese elderly people. Geriatr Gerontol Int. 2008;8:143-51.

72. Warner ET, Wolin KY, Duncan DT, et al. Differential accuracy of physical activity self-report by body mass index. Am J Health Behav. 2012;36:168-78.

73. Johnson-Kozlow M, Sallis JF, Gilpin EA, et al. Comparative validation of the IPAQ and the 7-Day PAR among women diagnosed with breast cancer. Int J Behav Nutr Phys Act. 2006;3:7.

74. Johnson-Kozlow M, Rock CL, Gilpin EA, et al. Validation of the WHI brief physical activity questionnaire among women diagnosed with breast cancer. Am J Health Behav. 2007;31:193-202.
75. Bray GA. In defense of a body mass index of 25 as the cut-off point for defining overweight. Obes Res. 1998;6:461-2.

76. Freedson PS, John D. Comment on "estimating activity and sedentary behavior from an accelerometer on the hip and wrist". Med Sci Sports Exerc. 2013;45:962-3.

77. Rosenberger ME, Haskell WL, Albinali F, et al. Estimating activity and sedentary behavior from an accelerometer on the hip or wrist. Med Sci Sports Exerc. 2013:45:964-75.

78. Esliger DW, Rowlands AV, Hurst TL, Catt M, Murray P et al. Validation of the GENEA Accelerometer. Med Sci Sports Exerc. 2011;43(6):1085-93. doi:10. 1249/MSS.0b013e31820513be.PubMed PMID: 21088628.

79. Zhang S, Rowlands AV, Murray P, Hurst TL. Physical activity classification using the GENEA wrist-worn accelerometer. Med Sci Sports Exerc. 2012;44: 742-8.

80. Helmerhorst HJ, Brage S, Warren J, et al. A systematic review of reliability and objective criterion-related validity of physical activity questionnaires. Int J Behav Nutr Phys Act. 2012;9:103.

81. van Poppel MN, Chinapaw MJ, Mokkink LB, et al. Physical activity questionnaires for adults: a systematic review of measurement properties. Sports Med. 2010;40:565-600.

82. Rzewnicki R, Vanden Auweele Y, De Bourdeaudhuij I. Addressing overreporting on the International Physical Activity Questionnaire (IPAQ) telephone survey with a population sample. Public Health Nutr. 2003;6:299-305.

83. Bassett Jr DR, Ainsworth BE, Swartz AM, et al. Validity of four motion sensors in measuring moderate intensity physical activity. Med Sci Sports Exerc. 2000:32:S471-480

84. U.S. Department of Health and Human Services. Physical Activity and Health: A Report of the Surgeon General. Atlanta: Department of Health and Human Services Centers for Disease Control and Prevention National Center for Chronic Disease Prevention and Health Promotion; 1996.

85. Washburn RA, Smith KW, Jette AM, Janney CA. The Physical Activity Scale for the Elderly (PASE): development and evaluation. J Clin Epidemiol. 1993:46:153-62.

86. Bland J, Altman D. Statistical methods for assessing agreement between two methods of clinical measurement. Lancet. 1986:8:307-10.

87. Schmidt ME, Steindorf K. Statistical methods for the validation of questionnairesdiscrepancy between theory and practice. Methods Inf Med. 2006:45:409-13.

88. Siebeling $L$, Wiebers $S$, Beem $L$, et al. Validity and reproducibility of a physical activity questionnaire for older adults: questionnaire versus accelerometer for assessing physical activity in older adults. Clin Epidemiol. 2012:4:171-80.

89. Wollmerstedt N, Noth U, Ince A, et al. The Daily Activity Questionnaire: a novel questionnaire to assess patient activity after total hip arthroplasty. J Arthroplasty. 2010;25:475-80. e471-473.

90. Moher D, Liberati A, Tetzlaff J, et al. Preferred reporting items for systematic reviews and meta-analyses: the PRISMA statement. PLoS Med. 2009;6:e1000097.

\section{Submit your next manuscript to BioMed Central and we will help you at every step:}

- We accept pre-submission inquiries

- Our selector tool helps you to find the most relevant journal

- We provide round the clock customer support

- Convenient online submission

- Thorough peer review

- Inclusion in PubMed and all major indexing services

- Maximum visibility for your research

Submit your manuscript at www.biomedcentral.com/submit

) Biomed Central 